\title{
Cervical human papillomavirus and HIV infection in women of child-bearing age in Abidjan, Côte d'lvoire, 2010
}

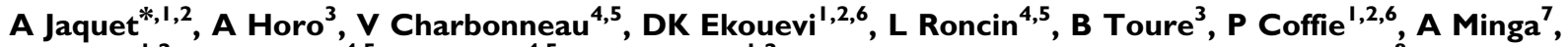 \\ A) Sasco ${ }^{1,2}$, I Garrigue $^{4,5}$, H Fleury ${ }^{4,5}$ and F Dabis ${ }^{1,2}$ for the leDEA West Africa collaboration ${ }^{8}$ \\ 'Université Bordeaux, ISPED, Centre INSERM U897- Epidémiologie-Biostatistique, F-33000 Bordeaux, France; ${ }^{2}$ INSERM, ISPED, Centre INSERM \\ U897- Epidémiologie-Biostatistique, F-33000 Bordeaux, France; '3envice de Gynécologie Obstétrique, CHU de Yopougon, Abidjan, Côte d'lvoire; \\ ${ }^{4} \mathrm{CHU}$ Bordeaux, Laboratoire de Virologie et Pôle de Biologie, Bordeaux, France; ${ }^{5}$ Université Bordeaux, Microbiologie Fondamentale et Pathogénicité \\ UMR 5234, F-33000 Bordeaux, France; ${ }^{6}$ Programme PAC-Cl, CHU de Treichville, Abidjan, Côte d'lvoire; ${ }^{7}$ Centre médical de suivi des donneurs de sang \\ (CMSDS), Centre National de Transfusion Sanguine d'Abidjan (CNTS), Abidjan, Cote d'lvoire
}

BACKGROUND: We sought to document the association of Human immunodeficiency Virus (HIV) infection and immunodeficiency with oncogenic Human Papillomavirus (HPV) infection in women with no cervical neoplastic lesions identified through a cervical cancer screening programme in Côte d'lvoire.

METHODS: A consecutive sample of women stratified on their HIV status and attending the national blood donor clinic or the closest HIV clinic was recruited during a cervical cancer screening programme based on the visual inspection. Diagnosis of HPV infection and genotype identification were based on the Linear Array; HPV test.

RESULTS: A total of 445 (254 HIV-positive and I9I HIV-negative) women were included. The prevalence of oncogenic HPV infection was 53.9\% (95\% confidence interval (Cl) 47.9-59.9) in HIV-positive women and 33.7\% (95\% Cl 27.I-40.3) in HIV-negative women (odds ratio $(\mathrm{OR})=2.3\left(95 \% \mathrm{Cl}\right.$ l.5-3.3)). In multivariate analysis, HIV-positive women with a CD4 count $<200$ cells mm ${ }^{3}$ or between 200 and 499 cells $\mathrm{mm}^{3}$ were more likely to harbour an oncogenic HPV compared with women with a CD4 count $\geqslant 500$ cells $\mathrm{mm}^{3}$ with OR of $2.8(95 \% \mathrm{Cl} \mathrm{I.I-8.I)}$ and $1.7(95 \% \mathrm{Cl}$ I.0-2.9), respectively.

CONCLUSION: A high prevalence of oncogenic HPV was found in women with no cervical neoplastic lesions, especially in HIV-positive women. Despite antiretroviral use, immunodeficiency was a main determinant of the presence of oncogenic HPV.

British Journal of Cancer (2012) I 07, 556-563. doi:I0.1038/bjc.2012.299 www.bjcancer.com

Published online 10 July 2012

(C) 2012 Cancer Research UK

Keywords: human papillomavirus; cervical cancer; HIVIAIDS; sub-Saharan Africa

Estimates of the incidence and mortality related to invasive cervical cancer (ICC) in sub-Saharan Africa are among the highest in the world with age-standardised rates of 31.7 per $10^{5}$ and 22.5 per $10^{5}$ persons per year, respectively (Ferlay et al, 2010). Oncogenic Human Papillomavirus (HPV) is the necessary cofactor for ICC and its histological precursor, cervical intraepithelial neoplasia (CIN) (Walboomers et al, 1999; Munoz et al, 2003). With a relatively long natural history (several years between HPV infection, the occurrence of precancerous lesions and their progression to invasive stages), as well as the availability of screening tests, ICC is amenable to prevention strategies including screening and vaccination. Yet, conventional cervical screening based on cytology is not sustainable in most resource-limited countries and alternative methods such as visual inspection or HPV tests have been recently developed (Cuzick et al, 2008; Qiao et al, 2008). Additionally, vaccines targeting a limited number of oncogenic HPV types (16 and 18) are currently marketed in some African countries (Harries et al, 2009). In 2011, Rwanda has been the first country in Africa to implement a national prevention

*Correspondence: Dr A Jaquet;

E-mail: antoine.jaquet@isped.u-bordeaux2.fr

${ }^{8}$ See Appendix.

Received I March 2012; revised II June 2012; accepted I4 June 2012; published online 10 July 2012 programme for cervical cancer including HPV vaccination (Anonymous, 2011). Previous reports conducted in sub-Saharan Africa have documented an association between Human immunodeficiency Virus (HIV) and oncogenic HPV infection in a time of limited access to antiretroviral treatment (ART) (Sahasrabuddhe et al, 2007; Yamada et al, 2008; Firnhaber et al, 2009). However, the epidemiology of HPV infection according to HIV status is not well described in many African countries and might directly impact on the efficacy of cervical-screening tests based on HPV detection, as well as of HPV vaccination. Since 2002, access to ART has dramatically improved with now five million of HIV-infected patients on treatment in sub-Saharan Africa. Moreover, ART has been provided free of charge in countries like Côte d'Ivoire, since 2008 (Eholie et al, 2009; UNAIDS, 2011). The aim of the present study was to document the association of HIV infection and its related immunodeficiency on cervical oncogenic HPV infection in women of child-bearing age in the ART era in Abidjan, Côte d'Ivoire.

\section{PATIENTS AND METHODS}

\section{Study population}

A cervical cancer screening programme based on visual inspection methods has been implemented in the ART clinics in Abidjan, part of 'the International epidemiological Database to Evaluate AIDS 
(IeDEA) West Africa collaboration' (Ekouevi et al, 2010). The main procedures of this cervical cancer screening have been described elsewhere (Horo et al, 2012). The screening procedure was conducted in the national centre for blood transfusion 'Centre National de Transfusion Sanguine' (CNTS) and its attached HIV clinic. An itinerant team composed of three certified midwives was in charge of proposing cervical cancer screening to all HIVpositive women attending the HIV clinic for their routine HIV follow-up, as well as all women who attended the CNTS for blood donation, with a documented negative HIV status. All HIVpositive women included in the present study were positively tested for HIV infection according to the national algorithm for HIV testing in Côte d'Ivoire. To enhance participation to the cervical cancer screening, group counselling was provided by midwives on a daily basis in the waiting rooms of the HIV clinic and the CNTS. Identical exclusion criteria (i.e., positive history of cervical cancer or total hysterectomy, age $<25$ or $>65$ years, pregnancy over 20 weeks) were applied to both HIV-negative and HIV-positive women. All women who underwent the present cervical cancer screening programme had never been screened for cervical disease before this study. Women with positive visual inspection were systematically referred to a medical consultation for colposcopy and directed biopsy samples if needed. Women with cervical neoplastic disease were offered appropriate follow-up and treatment according to local recommendations (i.e., cryotherapy, cold knife cone surgery or extended hysterectomy). The entire screening procedure was free of charge, as well as the ensuing treatment in case of positive findings. From June to October 2010, a subset of women screened with visual inspection methods also underwent a systematic cervical sample collection for HPV genotyping during 1 week per month in each of these two clinics. This study was approved by the national ethics committee for HIV research in Côte d'Ivoire.

\section{Study conduct and sample collection}

After obtaining written consent from the women, midwives collected information related to socio-demographic characteristics including age, formal education, marital status, number of lifetime sexual partners, number of gestations and parity. After the participant's history was taken, a gynaecological examination was conducted. Midwives inserted a sterile Dacron swab and rotated the swab three times at the level of the squamocolumnar junction (SCJ). The swab was then placed in the transport solution, kept on ice and transported back to the Pasteur institute in Abidjan. The midwife then applied a five percent acetic acid solution to the cervix for visual inspection with acetic acid (VIA). A positive VIA was characterised by a well-defined, dense acetowhite area with regular or irregular margins, close to or abutting the SCJ in the transformation zone or when the whole cervix or a cervical growth turned acetowhite. Following VIA, visual inspection with Lugol's iodine (VILI) was also performed. A positive VILI test was characterised by a dense, thick, bright, mustard-yellow or saffron-yellow iodine non-uptake area seen in the transformation zone, close to or abutting the SCJ or when the entire cervix or a cervical growth turns densely yellow. Results of VIA and VILI were both classified as negative, positive or positive with suspicion of ICC according to the International Agency for Research on Cancer (IARC) training manual and recorded on the study questionnaire following each test (Sankaranarayanan and Wesley, 2003). Back to the laboratory, the swabs were stirred into a transport solution composed of $0.5 \%$ phenol red, tryptose-phosphate, and an association of antibiotics (Penicillin, Streptomycin and Gentamycin). The solution was then adjusted for a $\mathrm{P}_{\mathrm{H}}$ value of 7.2 , filtered at $0.2 \mu \mathrm{m}$ and frozen at $-80^{\circ} \mathrm{C}$. Samples were shipped frozen to the virology unit of Bordeaux University and stored at $-80{ }^{\circ} \mathrm{C}$ until the time of assay.

\section{HPV detection and typing}

The MagNAPure LC 2.0 system (Roche Diagnostics GmbH, Mannheim, Germany) was used for DNA isolation from $200 \mu \mathrm{l}$ of cervical samples with MagNAPure LC Total Nucleic Acid Isolation kit (Roche Diagnostics $\mathrm{GmbH}$ ), following the instructions of the manufacturer. Nucleic acids were eluted in $100 \mu \mathrm{l}$ of elution buffer and $50 \mu \mathrm{l}$ were used for PCR. The integrity of the DNA samples was ascertained by positive amplification of human DNA ß-globin control. Human Papillomavirus amplification, hybridisation and detection were performed with the Linear Array HPV Genotyping Test following Roche instructions (Roche Diagnostics GmbH). Briefly, this method is based on the amplification of a $450 \mathrm{pb}$ sequence within the L1 region using PGMY primers, a consensus mixture of oligonucleotide probes designed to amplify HPV-DNA from 37 anogenital genotypes by PCR method. Individual HPV types were considered as oncogenic HPVs if classified as carcinogenic (group 1: 16, 18, 31, $33,35,39,45,51,52,56,58$ and 59) or probably carcinogenic to humans (group 2A: 68) according to IARC monographs (IARC, 2007, 2011). In case of HPVs 33, 35 and/or 58 infections, the linear arrays algorithm is unable to prove the presence or absence of HPV 52 infection and consider this genotype as possibly present.

\section{Statistical analysis}

Human Papillomavirus frequencies were estimated according to HIV status and age classes and compared using two-sided $P$-values of the $\chi^{2}$ test or the Cochran-Armitage trend test when appropriate. Non-normally distributed variables such as the number of oncogenic HPV co-infection were compared with the Wilcoxon signed-rank test according to CD4 $+\mathrm{T}$ cell (CD4) count $\left(<200\right.$ cells $\mathrm{mm}^{3}$ vs $\geqslant 200$ cells $\left.\mathrm{mm}^{3}\right)$ in HIV-positive women. A logistic regression model was used for univariate and multivariate analyses of the demographic (age, formal education, marital status, age at first sexual intercourse, lifetime number of sexual partners and pregnancies) and clinical (CD4 count at first clinical follow-up visit, last known CD4 count measurement, ART use) determinants associated with at least one oncogenic HPV infection. For the multivariate analysis, a stepwise descending procedure was applied to derive the model that best predicted the presence of any oncogenic HPV. The goodness of fit of the model was assessed using the Akaike Information Criterion (AIC), a lower value of the AIC suggesting a better prediction of the model. All relevant potential confounders documented in the present study were included in the initial multivariate model (Table 1). Confounders that were not significantly associated with the presence of any oncogenic HPV and did not add any significant prediction to the model based on the AIC were sequentially removed. Before that, the absence of collinearity between quantitative variables (CD4 count measurements and the duration of ART) was checked to ensure the stability of estimated odds ratio (OR) when both present in the initial multivariate model. Proportions and OR estimates were reported with their 95\% confidence intervals ( $95 \%$ CIs). All statistical analyses were performed using SAS software, version 9.2 (SAS Institute Inc., Cary, NC, USA).

\section{RESULTS}

\section{Population characteristics}

Of the 1940 women who attended the CNTS and its HIV clinic for cervical cancer screening from May to November 2010, cervical samples were obtained from 510 women consecutively enrolled in the five 1-week periods of inclusion. Forty seven samples were secondarily excluded from the study (31 samples damaged during 
Table I Factors associated with the presence of at least one oncogenic HPV infection in HIV-positive women with no cervical neoplastic disease $(n=254)$ (leDEA West Africa collaboration 2010)

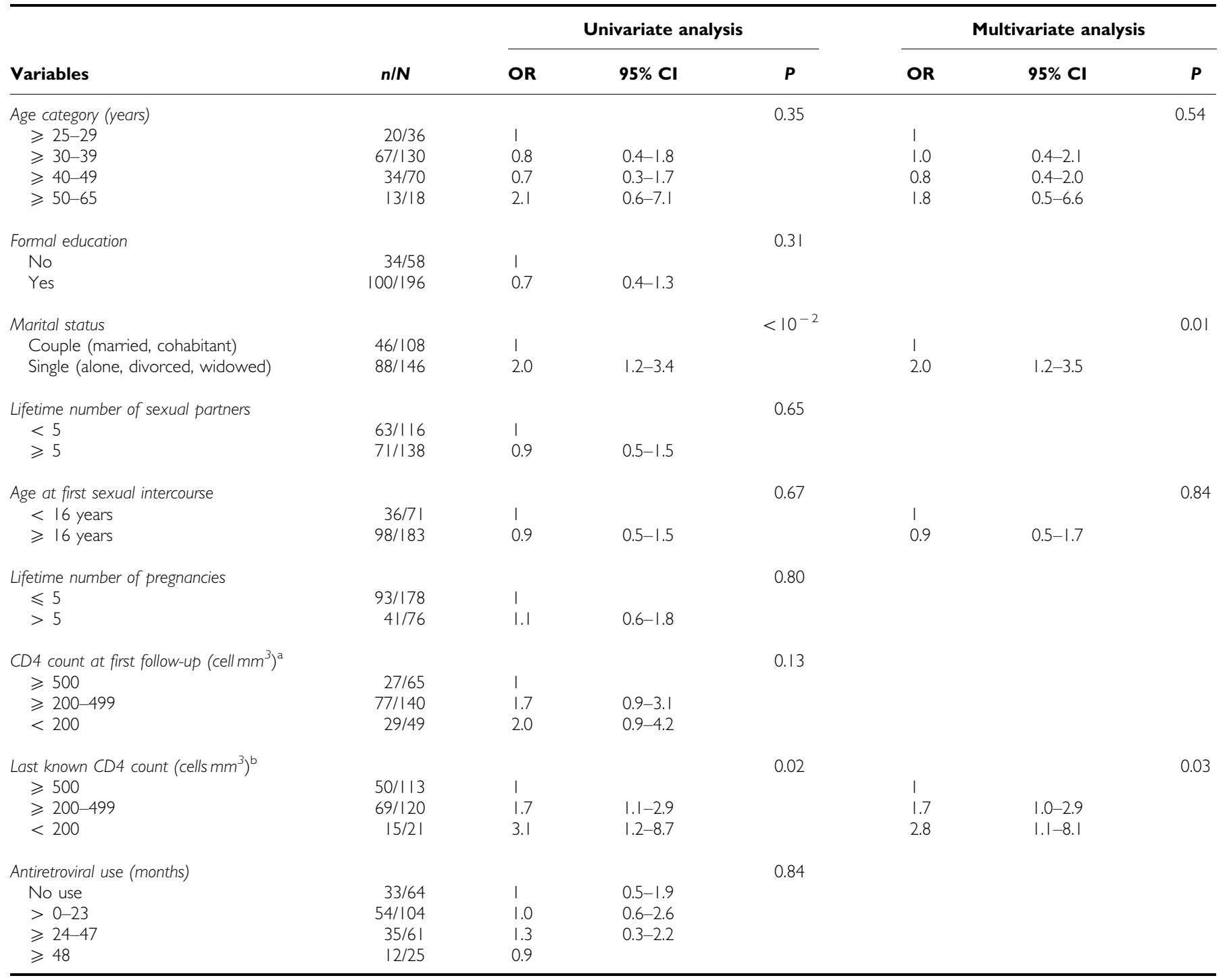

Abbreviations: $\mathrm{Cl}$ = confidence interval; HIV, Human immunodeficiency Virus; HPV, Human Papillomavirus; leDEA = International epidemiological Database to Evaluate AIDS; $\mathrm{OR}=$ odds ratio. ${ }^{\mathrm{a}} \mathrm{CD} 4$ count measured during first clinical follow-up visit for HIV infection. ${ }^{b}$ Last known $\mathrm{CD} 4$ count measure at the time of the cervical cancer screening procedure.

shipment and 16 misidentified samples). Overall, 463 women had documented HPV status. The rates of positive visual inspection were $11.2 \%$ in the 267 HIV-positive and $5.1 \%$ in the $196 \mathrm{HIV}$ negative women. These figures did not significantly differ from the one observed in the remaining $740 \mathrm{HIV}$-positive and 728 HIV-negative women who attended the cervical cancer screening during the study period, but did not benefit from the HPV genotyping ( $P$-values of 0.15 and 0.43 , respectively). A total of 18 CIN were identified, including 16 CIN of grade 1 , one CIN of grade 2 and one ICC. Analyses of factors associated with oncogenic HPV were restricted to the remaining 445 women (254 HIVpositive and $191 \mathrm{HIV}$-negative) with no cervical neoplastic disease. The median (interquartile range (IQR)) age was 36 (IQR 32-42) years in HIV-positive women and 35 (IQR 30-44) years in HIV-negative women $(P=0.47)$. The $254 \mathrm{HIV}$-positive women presented with a median CD4 count at last known follow-ups of 471 (IQR 318-629) cells $\mathrm{mm}^{3}$. Their median time since first clinical follow-up was 31.5 (IQR 17-61) months; $190 \mathrm{HIV}$-positive women $(74.8 \%)$ were on ART for a median duration of 21 (IQR 7-35) months.

\section{Genital HPV frequency and distribution}

All genital samples were positive for beta-globin DNA. The frequency of infection with HPV of any type and of oncogenic HPV was $72.4 \%$ (95\% CI 66.9-77.9) and 52.8\% (95\% CI 46.6-58.9) in HIV-positive women. In HIV-negative women, the corresponding figures were $50.3 \%$ (95\% CI $43.2-57.3)$ and $33.0 \%$ (95\% CI $26.3-39.6)$, that is, systematically lower $\left(P\right.$-values $<10^{-4}$ in both cases). Infections with multiple HPV types were more frequent in HIV-positive women (47.6\%) compared with HIV-negative women $(26.7 \%),\left(P<10^{-4}\right)$. Infections with multiple oncogenic HPV types were also more frequent in HIV-positive women $(24.0 \%)$ compared with HIV-negative women $(13.6 \%),\left(P<10^{-2}\right)$. In HIV-positive women, HPV 35 (15.7\%), 16 (14.2\%), $18(11.4 \%)$ and $58(11.4 \%)$ were the four most common HPV types identified. 

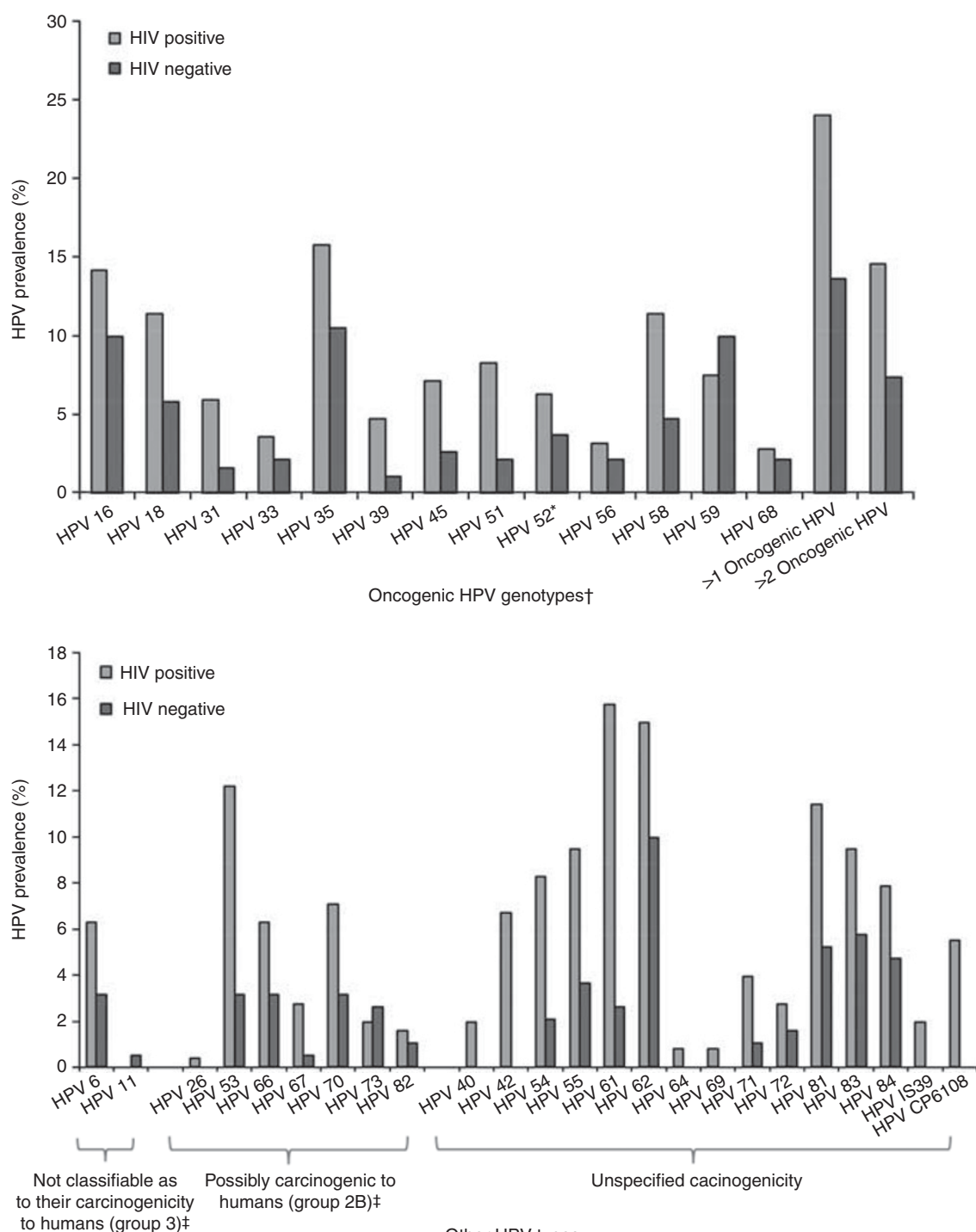

Other HPV types

Figure I Distribution of HPV genotypes according to HIV status among women with no cervical neoplastic disease in Abidjan, Côte d'Ivoire ( $n=445)$. International epidemiological Database to Evaluate AIDS West Africa collaboration 20 I0. *HPV 52 present without any co-infection HPV 33,35 or 58 , the probe for detection of HPV 52 cross reacts with HPV 33, 35 and 58. In case of infection with HPV 33,35 and/or 58, the presence of HPV 52 cannot be proved. ${ }^{\dagger}$ Defined as carcinogenic (group I: I6, I 8, 3I, 33, 35, 39, 45, 5I, 52, 56, 58 and 59) or probably carcinogenic to humans (group 2A: 68) according to IARC monographs. ${ }^{\ddagger}$ According to IARC monographs.

In HIV-negative women, HPV 35 (10.5\%), 16 (10.0\%) and 59 $(10.0 \%)$ were the three most frequent types identified followed by HPV 18 (5.8\%) (Figure 1).

In HIV-negative women, oncogenic HPV detection significantly decreased with increasing age at enrolment $(45.5 \% \geqslant 25-29$ years, $33.3 \% \geqslant 30-39$ years, $26.8 \% \geqslant 40-49$ years and $20.0 \% \geqslant 50-65$ years) $(P$ for trend $=0.01$ ) but not in HIV-positive women $(55.6 \%$ $\geqslant 25-29$ years, $51.5 \% \geqslant 30-39$ years, $48.6 \% \geqslant 40-49$ years and $72.2 \% \geqslant 50-65$ years $)(P$ for trend $=0.62)$ (Figure 2 ).

\section{Factors associated with oncogenic HPV infection}

In the multivariate analysis (Table 1), a low CD4 count at the time of cervical screening was associated to the presence of oncogenic HPV. Compared with women with a CD4 count $\geqslant 500$ cells $^{3}$, women with CD4 count $\geqslant 200-499$ cells $\mathrm{mm}^{3}$ and women with CD4 count $<200$ cells $\mathrm{mm}^{3}$ were at higher risk of harbouring $\geqslant 1$ oncogenic HPV with adjusted ORs of 1.7 (95\% CI 1.0-2.9) and 2.8 (95\% CI 1.1-8.1), respectively. Conversely, the level of CD4 count at initial clinical visit after HIV diagnosis was not linked to oncogenic HPV infection $(P=0.13)$. When comparing women not on ART $v s$ women on ART for different periods of time $(>0-23$ months, $\geqslant 24-47$ months and $\geqslant 48$ month), ART use as well as its duration were not associated with the presence of any oncogenic HPV $(P=0.84)$.

A sub-analysis restricted to HIV-positive women harbouring oncogenic HPV showed that women with a CD4 count $<200$ cells $\mathrm{mm}^{3}$ were infected with a median number of 3 (IQR 1-4) different oncogenic HPV vs 1 (IQR $1-3$ ) oncogenic HPV in women with CD4 count $\geqslant 200$ cells $\mathrm{mm}^{3}\left(P<10^{-2}\right)$.

\section{DISCUSSION}

\section{HPV frequency and distribution}

In the present study, HIV infection was associated with a higher frequency of oncogenic HPV infection as reported in other African 


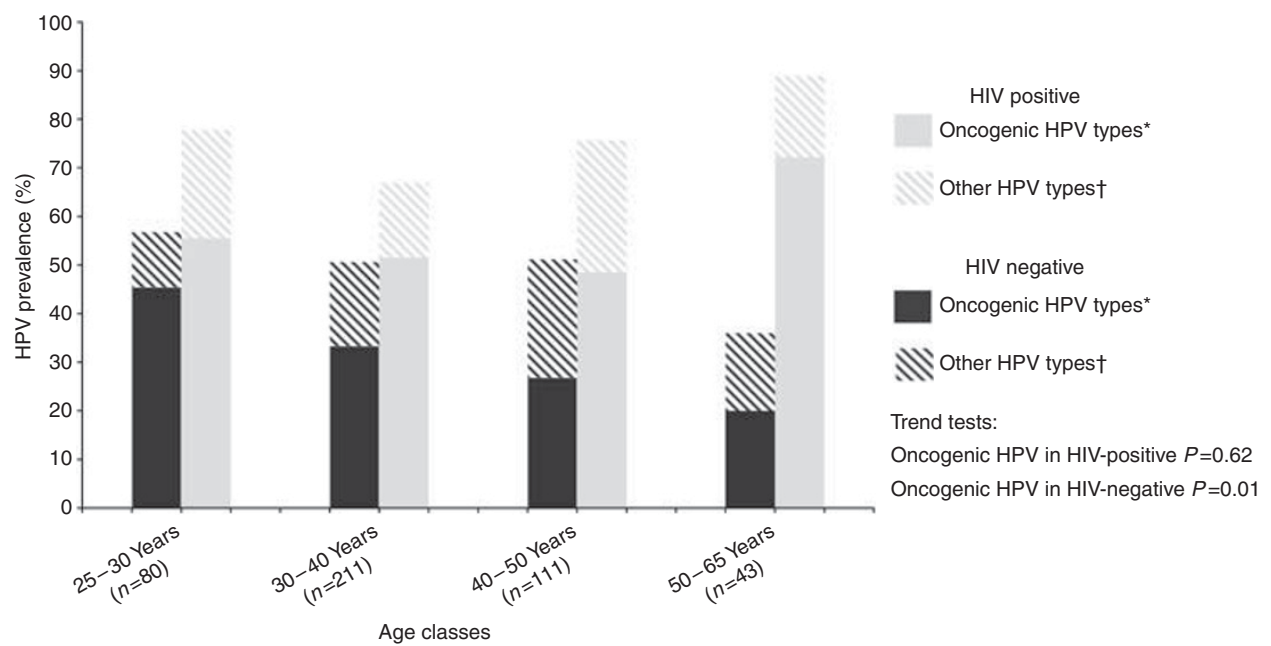

Figure 2 HPV distribution according to age classes in HIV-positive $(n=254)$ and HIV-negative women $(n=|9|)$ with no cervical neoplastic disease in Abidjan, Côte d'Ivoire. International epidemiological Database to Evaluate AIDS West Africa collaboration 20 I0. * Defined as carcinogenic (group I: I6, I8, $31,33,35,39,45,51,52,56,58$ and 59 ) or probably carcinogenic to humans (group 2A: 68) according to IARC monographs. ${ }^{\dagger}$ Defined as possibly carcinogenic to humans (Group 2B), not classifiable as to their carcinogenicity to humans (Group 3) or unspecified carcinogenicity according to IARC monographs.

countries (Didelot-Rousseau et al, 2006; Safaeian et al, 2008; Yamada et al, 2008; Singh et al, 2009; Luchters et al, 2010). Multiple infections with oncogenic HPV were also significantly more common in HIV-positive women. A higher rate of concurrent oncogenic HPV infection in HIV-positive women might challenge the proper role of specific oncogenic HPV types in the occurrence of ICC. There have been debates on the impact of HIV infection in the occurrence and persistence of HPV 16 and 18 types raising the fear that currently available vaccines may prevent a smaller proportion of ICC in HIV-positive women (Strickler $e t a l$, 2003; Clifford et al, 2006). Recent findings from sub-Saharan Africa have reported a similar frequency of HPV 16/18 in HIVpositive and HIV-negative women with ICC (De Vuyst et al, 2012). As our present report does not focus on women with cervical neoplastic disease, we were not able to add relevant information to this issue but the high frequency of multiple oncogenic HPV infection encountered in HIV-positive women stresses the need for a careful assessment of the efficacy of HPV vaccines, as well as HPV screening tests in sub-Saharan Africa. However, these concerns do not question the need to roll out HPV vaccination programs in sub-Saharan Africa as HPV 16 and 18 remain the most frequent types present in women with ICC so far (de Sanjose et al, 2010).

HPV 16 and 35 were the two most prevalent types reported, regardless of HIV status, in women with no cervical neoplastic disease. These findings are consistent with a report from Nigeria where HPV 16 and 35 were the most prevalent types in women with or without cytological abnormalities (Thomas et al, 2004). Nevertheless, our findings do not give indication on the respective role of HPV 16 and 35 on the occurrence of ICC. A recent report from Nigeria comparing the distribution of HPV infection in a group of women from the general population to a group of women with ICC showed that HPV 16 and 35 were the two most important and equally frequent types in the first group but women with ICC were predominantly infected with HPV 16 (Okolo et al, 2010). The frequency HPV 35 (5.9\%) was clearly less represented compared with the frequency HPV $16(67.8 \%)$ in women with ICC. However, HPV 35 does still account for a substantial fraction of ICC and might be considered for new generation vaccines. A study on HPV prevalence and associated cervical lesions was conducted in Côte d'Ivoire more than 15 years ago but there was a lack of information on detailed HPV types. Indeed, in this case-control study,
La Ruche et al (1998) found a low prevalence of HPV 35, irrespective of cytological status. This discordant result in the HPV 35 prevalence might be related to the primers pair used in those studies (MY09/MY11). The use of standardised PGMY primers pools instead of degenerate primers, as well as GP5 $+/ 6+$ primers has been estimated to be 5000 times more sensitive in the detection of the HPV 35 (Qu et al, 1997; Gravitt et al, 2000; Coutlee et al, 2002). Thus, early studies on HPV prevalence including the one conducted in Côte d'Ivoire have probably underestimated the true occurrence of HPV 35 infection. HPV 35 seems to be particularly frequent in the West-African women with no cervical neoplastic disease, regardless of HIV status. Although HPV 16 seems to have a major role in the occurrence of ICC from the current literature, additional documentation on the epidemiology of other HPV types such as HPV 35 among women with ICC using standardised methods is needed.

\section{Factors associated with oncogenic HPV}

Age The age-specific prevalence of oncogenic HPV infection observed in HIV-negative women follows the pattern of many sexually transmissible infections with a peak at younger ages and a significant decrease overtime as reported elsewhere in sub-Saharan Africa (De Vuyst et al, 2003; Baay et al, 2004; Said et al, 2009). Other reports have observed a high HPV prevalence in middle ( $>30-39$ years) and older age groups ( $\geqslant 40$ years) but reasons for such discrepancies have not been well explored so far (Xi et al, 2003; Keita et al, 2009). In our study, HIV-positive women presented with a high and sustained oncogenic HPV frequency across age classes. This finding is in accordance with a prior report from Burkina Faso and might reflect the impact of HIV-related immunodeficiency on persistence of HPV infection acquired in early sexual activity (Didelot-Rousseau et al, 2006). This high and sustained rate of oncogenic HPV infection during all the childbearing period in HIV-positive women might have a direct impact on the predictive values of HPV-based cervical-screening tests, which will need further evaluation in this context (Gage et al, 2012).

Sexual and reproductive characteristics Neither the reported number of lifetime sexual partners nor the age at first sexual intercourse was found to be associated with the presence of 
oncogenic HPV. This is an unexpected negative finding as these two factors are known risk factors for the acquisition of HPV infection. One explanation could be that the effect of variations in individual sexual habits becomes difficult to detect in HIV-positive population where the background prevalence of sexually transmitted disease exceeds a certain threshold (Thomas et al, 2004). Also, the collection of sexual habits might possibly be more subject to prevarication biases compared with other individual characteristics. We found that marital status was significantly associated with harbouring an oncogenic HPV. This variable could be interpreted as a proxy for the current number of sexual partners and less subject to prevarication or recall biases.

Immunologic status and ART use Previous studies have linked a severe immunodeficiency (CD4 count $<200$ cells $\mathrm{mm}^{3}$ ) with oncogenic HPV in cross-sectional studies in sub-Saharan Africa (Sahasrabuddhe et al, 2007; Yamada et al, 2008; Firnhaber et al, 2009). These results were observed in a period of limited access to ART. Our report focused on patients with a relatively preserved

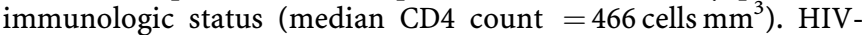
positive women with a last known CD4 count measure below $\leqslant 500$ cells $\mathrm{mm}^{3}$ were at higher risk of harbouring an oncogenic HPV. These findings suggest that reaching an optimal immunologic recovery might limit oncogenic HPV infections in HIVpositive women. It might thus have the potential ability to impact on the occurrence of precancerous cervical lesions leading to ICC. We found no association between any ART use and the presence of at least one oncogenic HPV. The cross-sectional nature of our study design prevents from drawing any temporal effect of ART use on HPV frequency. However, the precise impact of ART initiation on the incidence of new HPV infection or the clearance of already existing HPV infection is still debated (Lillo et al, 2001; Paramsothy et al, 2009; Minkoff et al, 2010). Data from Africa are sparse but in a prior report from a cross-sectional study, exposure to ART was not associated with oncogenic HPV (Firnhaber et al, 2009). Through immunologic restoration, ART is likely to impact on HPV frequency but the specific role of ART on HPV incidence and/or clearance still needs to be demonstrated.

Limitations Owing to the limited number of adequate infrastructures to efficiently conduct a cervical cancer screening programme based on cytology in Côte d'Ivoire, visual inspection methods were chosen for the screening of precancerous lesions of the cervix and ICC in HIV clinics. The limited performances of these screening tools in terms of sensitivity, specificity and predictive values prevented a full assessment of the true status related to cervical malignancy. Differences in methods for the HPV genotypes identification severely limit comparisons between studies. Because of cross-reactivity with HPV 33, HPV 35 and HPV 58, the Roche Linear Array HPV Genotyping test was not able to isolate the presence of HPV 52 in the case of co-infection with one of these other types. Thus, our present estimate of the HPV 52 prevalence is probably underestimated as a fraction of women infected with HPV 33, 35 and/or 58 might also harbour HPV 52 type. Previous reports have identified HPV 52 as one of the leading

\section{REFERENCES}

Anonymous (2011) Financing HPV vaccination in developing countries. Lancet 377: 1544

Baay MF, Kjetland EF, Ndhlovu PD, Deschoolmeester V, Mduluza T, Gomo E, Friis H, Midzi N, Gwanzura L, Mason PR, Vermorken JB, Gundersen SG (2004) Human papillomavirus in a rural community in Zimbabwe: the impact of HIV co-infection on HPV genotype distribution. J Med Virol 73: 481-485

Clifford GM, Goncalves MA, Franceschi S (2006) Human papillomavirus types among women infected with HIV: a meta-analysis. AIDS 20: 2337-2344 types in sub-Saharan Africa. Detection with a more discriminating assay will be needed in order to accurately estimate the HPV 52 prevalence.

\section{CONCLUSION}

The frequencies of oncogenic and multiple HPV infections are high in West Africa, especially in HIV-positive women. In a time of improved access to ART, an impaired immunological status was found to be a main determinant of oncogenic HPV infection in HIV-positive women. As opposed to HIV-negative women who present a significant decrease in oncogenic HPV frequency in older age classes, the frequency of oncogenic HPV infection remained high in all age classes of HIV-positive women. The persistence of HPV infection potentially mediated by immunodeficiency might explain the sustained level of oncogenic HPV infection while HPV infection significantly decreased over age in HIV-negative women. A prospective assessment of the impact of ART use and immunodeficiency on the occurrence and persistence of oncogenic HPV infection is now needed in order to provide a more comprehensive understanding of the interactions between HIV and HPV infections in sub-Saharan Africa and design adapted screening programmes.

\section{ACKNOWLEDGEMENTS}

We are indebted to all of the women who agreed to participate in this present study, as well as to the midwives who performed the cervical screening and data collection. We are also indebted to the ISPED library team for its bibliographical assistance. We thank $\mathrm{Mr}$ Kouassi Kra and Dr Edgard V Adjogoua for their critical help in the storage and shipment of cervical samples during the political crisis in Côte d'Ivoire. This work was funded by the following institutes: the National Cancer Institute (NCI), the Eunice Kennedy Shriver National Institute of Child Health \& Human Development (NICHD), the National Institute of Allergy and Infectious Diseases (NIAID) (grant no. 5U01AI069919).

\section{Conflict of interest}

The authors declare no conflict of interest.

\section{Author contribution}

$\mathrm{AJ}, \mathrm{AH}, \mathrm{DKE}, \mathrm{AJS}$ and $\mathrm{FD}$ designed the study; $\mathrm{AH}$ and $\mathrm{BT}$ conducted the clinical work (i.e., cervical-screening procedure, HPV collection). AJ, DKE, PAC and AH supervised the study; HPV identification and typing were supervised by VC, LR, IG and HF; statistical analysis was done by AJ. The manuscript was drafted by $\mathrm{AJ}$ and critical revision of the manuscript for important intellectual content was provided by all authors who commented on the original manuscript and agreed on the version finalised by AJ for submission.
Coutlee F, Gravitt P, Kornegay J, Hankins C, Richardson H, Lapointe N, Voyer H, Franco E (2002) Use of PGMY primers in L1 consensus PCR improves detection of human papillomavirus DNA in genital samples. J Clin Microbiol 40: 902-907

Cuzick J, Arbyn M, Sankaranarayanan R, Tsu V, Ronco G, Mayrand MH, Dillner J, Meijer CJ (2008) Overview of human papillomavirus-based and other novel options for cervical cancer screening in developed and developing countries. Vaccine 26(Suppl 10): K29-K41

de Sanjose S, Quint WG, Alemany L, Geraets DT, Klaustermeier JE, Lloveras B, Tous S, Felix A, Bravo LE, Shin HR, Vallejos CS, de Ruiz PA, Lima MA, 
Guimera N, Clavero O, Alejo M, Llombart-Bosch A, Cheng-Yang C, Tatti SA, Kasamatsu E, Iljazovic E, Odida M, Prado R, Seoud M, Grce M, Usubutun A, Jain A, Suarez GA, Lombardi LE, Banjo A, Menendez C, Domingo EJ, Velasco J, Nessa A, Chichareon SC, Qiao YL, Lerma E, Garland SM, Sasagawa T, Ferrera A, Hammouda D, Mariani L, Pelayo A, Steiner I, Oliva E, Meijer CJ, Al-Jassar WF, Cruz E, Wright TC, Puras A, Llave CL, Tzardi M, Agorastos T, Garcia-Barriola V, Clavel C, Ordi J, Andujar M, Castellsague X, Sanchez GI, Nowakowski AM, Bornstein J, Munoz N, Bosch FX (2010) Human papillomavirus genotype attribution in invasive cervical cancer: a retrospective cross-sectional worldwide study. Lancet Oncol 11: 1048-1056

De Vuyst H, Ndirangu G, Moodley M, Tenet V, Estambale B, Meijer CJ, Snijders PJ, Clifford G, Franceschi S (2012) Prevalence of human papillomavirus in women with invasive cervical carcinoma by HIV status in Kenya and South Africa. Int J Cancer 131: 949-955

De Vuyst H, Steyaert S, Van Renterghem L, Claeys P, Muchiri L, Sitati S, Vansteelandt S, Quint W, Kleter B, Van Marck E, Temmerman M (2003) Distribution of human papillomavirus in a family planning population in nairobi, kenya. Sex Transm Dis 30: 137-142

Didelot-Rousseau MN, Nagot N, Costes-Martineau V, Valles X, Ouedraogo A, Konate I, Weiss HA, Van de Perre P, Mayaud P, Segondy M (2006) Human papillomavirus genotype distribution and cervical squamous intraepithelial lesions among high-risk women with and without HIV-1 infection in Burkina Faso. Br J Cancer 95: 355-362

Eholie SP, Tanon KA, Folquet-Amorissani M, Ouattara I, Aba YT, TraoreEttiegne V, Kakou AR, Aoussi E, Anglaret X, Bissagnene E (2009) Impact of access to antiretroviral therapy in Cote d'Ivoire [Bilan de l'acces aux antiretroviraux en Côte d'Ivoire]. Med Trop (Mars) 69: 520-524

Ekouevi DK, Balestre E, Ba-Gomis FO, Eholie SP, Maiga M, Amani-Bosse C, Minga A, Messou E, Sow PS, Lewden C, Traore HA, Bissagnene E, Dabis F (2010) Low retention of HIV-infected patients on antiretroviral therapy in 11 clinical centres in West Africa. Trop Med Int Health 15(Suppl 1): 34-42

Ferlay J, Shin HR, Bray F, Forman D, Mathers C, Parkin DM (2010) GLOBOCAN 2008, Cancer Incidence and Mortality Worldwide: IARC CancerBase No. 10 [Internet]. Lyon, France: International Agency for Research on Cancer. Available from: http://globocan.iarc.fr, last accessed $01 / 15 / 12$

Firnhaber C, Van Le H, Pettifor A, Schulze D, Michelow P, Sanne IM, Lewis DA, Williamson AL, Allan B, Williams S, Rinas A, Levin S, Smith JS (2009) Association between cervical dysplasia and human papillomavirus in HIV seropositive women from Johannesburg South Africa. Cancer Causes Control 21: 433-443

Gage JC, Ajenifuja KO, Wentzensen NA, Adepiti AC, Eklund C, Reilly M, Hutchinson M, Wacholder S, Harford J, Soliman AS, Burk RD, Schiffman M (2012) The age-specific prevalence of human papillomavirus and risk of cytologic abnormalities in rural Nigeria: implications for screen-andtreat strategies. Int J Cancer 130: 2111-2117

Gravitt PE, Peyton CL, Alessi TQ, Wheeler CM, Coutlee F, Hildesheim A, Schiffman MH, Scott DR, Apple RJ (2000) Improved amplification of genital human papillomaviruses. J Clin Microbiol 38: 357-361

Harries J, Moodley J, Barone MA, Mall S, Sinanovic E (2009) Preparing for HPV vaccination in South Africa: key challenges and opinions. Vaccine 27: $38-44$

Horo A, Jaquet A, Ekouevi DK, Toure B, Coffie PA, Effi B, Messou E, Minga A, Moh R, Kone M, Dabis F, Sasco AJ (2012) Cervical cancer screening by visual inspection in Cote d'Ivoire, operational and clinical aspects according to HIV status. BMC Public Health 12: 237

IARC (2007) Working Group on the Evaluation of Carcinogenic Risks to Humans. IARC Monographs on the Evaluation of Carcinogenic Risks to Humans, Human Papillomaviruses. Vol. 90. International Agency for Research on Cancer: Lyon

IARC (2011) Working Group on the Evaluation of Carcinogenic Risks to Humans. IARC Monographs on the evaluation of carcinogenic risks to humans, Biological agents. Vol 100B. International Agency for Research on Cancer: Lyon

Keita N, Clifford GM, Koulibaly M, Douno K, Kabba I, Haba M, Sylla BS, van Kemenade FJ, Snijders PJ, Meijer CJ, Franceschi S (2009) HPV infection in women with and without cervical cancer in Conakry, Guinea. Br J Cancer 101: 202-208

La Ruche G, You B, Mensah-Ado I, Bergeron C, Montcho C, Ramon R, Toure-Coulibaly K, Welffens-Ekra C, Dabis F, Orth G (1998) Human papillomavirus and human immunodeficiency virus infections: relation with cervical dysplasia-neoplasia in African women. Int J Cancer 76: 480-486

Lillo FB, Ferrari D, Veglia F, Origoni M, Grasso MA, Lodini S, Mastrorilli E, Taccagni G, Lazzarin A, Uberti-Foppa C (2001) Human papillomavirus infection and associated cervical disease in human immunodeficiency virus-infected women: effect of highly active antiretroviral therapy. J Infect Dis 184: 547-551

Luchters SM, Vanden Broeck D, Chersich MF, Nel A, Delva W, Mandaliya K, Depuydt CE, Claeys P, Bogers JP, Temmerman M (2010) Association of HIV infection with distribution and viral load of HPV types in Kenya: a survey with 820 female sex workers. BMC Infect Dis 10: 18

Minkoff H, Zhong Y, Burk RD, Palefsky JM, Xue X, Watts DH, Levine AM, Wright RL, Colie C, D'Souza G, Massad LS, Strickler HD (2010) Influence of adherent and effective antiretroviral therapy use on human papillomavirus infection and squamous intraepithelial lesions in human immunodeficiency virus-positive women. J Infect Dis 201: 681-690

Munoz N, Bosch FX, de Sanjose S, Herrero R, Castellsague X, Shah KV, Snijders PJ, Meijer CJ (2003) Epidemiologic classification of human papillomavirus types associated with cervical cancer. $N$ Engl J Med 348: 518-527

Okolo C, Franceschi S, Adewole I, Thomas JO, Follen M, Snijders PJ, Meijer CJ, Clifford GM (2010) Human papillomavirus infection in women with and without cervical cancer in Ibadan, Nigeria. Infect Agent Cancer 5: 24

Paramsothy P, Jamieson DJ, Heilig CM, Schuman PC, Klein RS, Shah KV, Rompalo AM, Cu-Uvin S, Duerr A (2009) The effect of highly active antiretroviral therapy on human papillomavirus clearance and cervical cytology. Obstet Gynecol 113: 26-31

Qiao YL, Sellors JW, Eder PS, Bao YP, Lim JM, Zhao FH, Weigl B, Zhang WH, Peck RB, Li L, Chen F, Pan QJ, Lorincz AT (2008) A new HPV-DNA test for cervical-cancer screening in developing regions: a cross-sectional study of clinical accuracy in rural China. Lancet Oncol 9: 929-936

Qu W, Jiang G, Cruz Y, Chang CJ, Ho GY, Klein RS, Burk RD (1997) PCR detection of human papillomavirus: comparison between MY09/MY11 and GP5 + /GP6 + primer systems. J Clin Microbiol 35: 1304-1310

Safaeian M, Kiddugavu M, Gravitt PE, Gange SJ, Ssekasanvu J, Murokora D, Sklar M, Serwadda D, Wawer MJ, Shah KV, Gray R (2008) Prevalence and risk factors for carcinogenic human papillomavirus infections in rural Rakai, Uganda. Sex Transm Infect 84: 306-311

Sahasrabuddhe VV, Mwanahamuntu MH, Vermund SH, Huh WK, Lyon MD, Stringer JS, Parham GP (2007) Prevalence and distribution of HPV genotypes among HIV-infected women in Zambia. Br J Cancer 96: 1480-1483

Said HM, Ahmed K, Burnett R, Allan BR, Williamson AL, Hoosen AA (2009) HPV genotypes in women with squamous intraepithelial lesions and normal cervixes participating in a community-based microbicide study in Pretoria, South Africa. J Clin Virol 44: 318-321

Sankaranarayanan R, Wesley RS (2003) A Practical Manual on Visual Screening for Cervical Neoplasia. [IARC Technical Publication No. 41]. IARC Press: Lyon

Singh DK, Anastos K, Hoover DR, Burk RD, Shi Q, Ngendahayo L, Mutimura E, Cajigas A, Bigirimani V, Cai X, Rwamwejo J, Vuolo M, Cohen M, Castle PE (2009) Human papillomavirus infection and cervical cytology in HIV-infected and HIV-uninfected Rwandan women. J Infect Dis 199: 1851-1861

Strickler HD, Palefsky JM, Shah KV, Anastos K, Klein RS, Minkoff H, Duerr A, Massad LS, Celentano DD, Hall C, Fazzari M, Cu-Uvin S, Bacon M, Schuman P, Levine AM, Durante AJ, Gange S, Melnick S, Burk RD (2003) Human papillomavirus type 16 and immune status in human immunodeficiency virus-seropositive women. J Natl Cancer Inst 95: 1062-1071

Thomas JO, Herrero R, Omigbodun AA, Ojemakinde K, Ajayi IO, Fawole A, Oladepo O, Smith JS, Arslan A, Munoz N, Snijders PJ, Meijer CJ, Franceschi S (2004) Prevalence of papillomavirus infection in women in Ibadan, Nigeria: a population-based study. Br J Cancer 90: 638-645

UNAIDS (2011) Global HIV/AIDS response: epidemic update and health sector progress towards universal access: progress report. UNAIDS. Geneva. Available at http://whqlibdoc.who.int/publications/2011/ 9789241502986_eng.pdf last accessed 01/15/12.

Walboomers JM, Jacobs MV, Manos MM, Bosch FX, Kummer JA, Shah KV Snijders PJ, Peto J, Meijer CJ, Munoz N (1999) Human papillomavirus is a necessary cause of invasive cervical cancer worldwide. J Pathol 189: 12-19

Xi LF, Toure P, Critchlow CW, Hawes SE, Dembele B, Sow PS, Kiviat NB (2003) Prevalence of specific types of human papillomavirus and cervical squamous intraepithelial lesions in consecutive, previously unscreened, West-African women over 35 years of age. Int J Cancer 103: 803-809

Yamada R, Sasagawa T, Kirumbi LW, Kingoro A, Karanja DK, Kiptoo M, Nakitare GW, Ichimura H, Inoue M (2008) Human papillomavirus infection and cervical abnormalities in Nairobi, Kenya, an area with a high prevalence of human immunodeficiency virus infection. J Med Virol 80: $847-855$ 


\section{APPENDIX}

The IeDEA West Africa Working Group is organised as follows:

- Primary Investigators: Pr François Dabis* (INSERM U897, ISPED, Bordeaux, France), Pr Emmanuel Bissagnene* (SMIT, CHU de Treichville, Abidjan, Côte d'Ivoire)

- Clinical Investigators by country and alphabetical order: Jocelyn Akakpo, Alain Azondékon, Jules Bashi, Sagbo Gratien, Sikiratou Koumakpaï, Marcel D Zannou* (Benin); Ye Diarra, Eric-Arnaud Diendere, Joseph Drabo*, Fla Koueta (Burkina Faso); Edmond Aka-Addi, Clarisse Amani-Bosse, Franck-Olivier Ba-Gomis, François Eboua-Tanoh, Serge-Paul Eholie*, Calixte Guehi, Kouakou Kouadio, Serge-Olivier Koulé, Eugène Messou, Albert Minga, Aristophane Tanon, Marguerite Timité-Konan, Pety Touré, (Côte d'Ivoire); Kevin Peterson* (Gambia); Bamenla Goka, Lorna Renner* (Ghana); Hadizatou Coulibaly, Fatoumata Dicko, Moussa Maiga*, Daouda Minta, Mariam Sylla, Hamar Alassane Traoré; Man Charurat* (Nigeria); Bernard Diop, Fatou Ly Ndiaye, Papa Salif Sow, Haby Signaté Sy* Judicaël Tine (Senegal)

- Epidemiology and Statistical Unit (INSERM U897, ISPED, Université Bordeaux Segalen, Bordeaux, France): Eric Balestre, Didier K Ekouévi*, Antoine Jaquet*, Valériane Leroy*, Charlotte Lewden*, Karen Malateste, Annie J Sasco, Rodolphe Thiebaut

- Data Management Unit (PAC-CI, CHU Treichville, Abidjan, Côte d'Ivoire): Gérard Allou, Jean Claude Azani, Patrick Coffie

- Administration: Alexandra Doring and Elodie Rabourdin (ISPED), Hughes Djétouan, Bertin Kouadio and Adrienne Kouakou (PAC-CI)
- Adult clinical centers by city and country: Abidjan, Côte d'Ivoire: Médecine Interne et Tropicale (SMIT), CHU de Treichville, Unité de Soins Ambulatoires et de Conseil (USAC), Centre Médical de Suivi de Donneurs de Sang/CNTS/PRIMO-CI, ACONDA-MTCT-Plus, ACONDA-CePReF, Centre Intégré de Recherche Bioclinique d'Abidjan (CIRBA) Abuja, Nigeria: University of Abuja Teaching Hospital (UATH). Bamako, Mali: Service d'Hépato-Gastro-Entérologie, Hôpital Gabriel Touré, Centre de Prise en Charge des Personnes vivant avec le VIH, Hôpital du Point G Dakar, Sénégal: Service des Maladies Infectieuses, CHU de FANN/ ISAARV. Banjul, Gambia: Fajara Cohort. Benin City, Nigeria: University of Benin Teaching Hospital (UBTH) Cotonou, Benin: Service de Médecine Interne, CNHU Hubert Maga. Ouagadougou, Burkina-Faso: Service de Médecine Interne, CHU Yalgado

- Paediatric clinical centers by city and country: Abidjan, Côte d'Ivoire: ACONDA-CEPREF, ACONDA-MTCT-Plus, CHU de Yopougon, Centre Intégré de Recherche Bioclinique d'Abidjan (CIRBA). Accra, Ghana: Korle Bu Teaching Hospital. Bamako, Mali: Hôpital Gabriel Touré. Cotonou, Benin: Centre National Hospitalo-Universitaire Hubert Maga, Hôpital d'Instruction des Armées. Dakar, Senegal: Hôpital d'Enfants Albert-Royer. Fajara, Gambia: Medical Research Council. Ouagadougou, Burkina-Faso: Centre Hospitalier Charles de Gaulle.

* Member of the IeDEA West Africa Technical Committee

This work is published under the standard license to publish agreement. After 12 months the work will become freely available and the license terms will switch to a Creative Commons Attribution-NonCommercial-Share Alike 3.0 Unported License. 